\title{
3 Research Suare \\ What is the added value of CT-angiography in patients with transient ischemic attack?
}

Gerrit U. Herpertz

Universitätsmedizin Göttingen Klinik für Neurologie https://orcid.org/0000-0002-7330-7121

Ilko L Maier ( $\square$ ilko.maier@med.uni-goettingen.de)

https://orcid.org/0000-0001-6988-8878

Mathias Bähr

Universitätsmedizin Göttingen Klinik für Neurologie

Marios-Nikos Psychiogios

Universitatsspital Basel

Jan Liman

Universitätsmedizin Göttingen Klinik für Neurologie

Research article

Keywords: TIA, CT-angiography, ABCD2, ABCD3, SPI-II, carotid stenosis

Posted Date: January 12th, 2021

DOI: https://doi.org/10.21203/rs.3.rs-64386/v3

License: (9) This work is licensed under a Creative Commons Attribution 4.0 International License.

Read Full License 


\section{Abstract}

Background Transient ischemic attack (TIA) is an important predictor for a pending stroke. Guidelines recommend similar workup for TIA-patients as for stroke patients to directly assess the extra- and intracranial arteries via Computed tomography angiography (CTA) regarding vascular pathologies with direct therapeutic implications. Aim of our study was a systematic analysis of CTA-findings in TIApatients and evaluate possible predictive TIA scores for ipsilateral vascular pathology.

Methods We analysed data from TIA patients, admitted to our University Medical Centre, between September 2015 and March 2018, to identify predictors for high-risk vascular pathologies, like high-grade stenosis, dissection, thrombi or occlusion and the for need for an intervention. Following subgroups were identified: 1) no- or low-grade-stenosis (<50\%) 2) ipsilateral high-risk vascular pathology and 3) high risk findings needing surgical or interventional treatment. As predictive tools for ipsilateral vascular findings we used the ABCD2-, the ABCD3- and the SPI-II score.

Results Of 833 patients, 549 (65.9\%) underwent initial CTA in the emergency department. In 126 (23.0\%) patients, ipsilateral vascular findings were identified from which 40 (7.3\%) needed treatment. The ABCD2-, ABCD3- and SPI-II-scores were not predictive for ipsilateral vascular pathologies. We identified coronary heart disease (OR 2.13, 1.35-3.39 95\% Cl; $\mathrm{p}=0.001)$ and short duration of symptoms (OR $0.7,0.55-0,89$ $95 \% \mathrm{Cl} ; \mathrm{p}=0.004)$ as predictors for ipsilateral vascular pathologies.

Conclusion More than every fifth TIA-patient had relevant vascular findings revealed by acute CTA. TIAscores were not predictive for these findings. Patients with a history of coronary heart disease and short duration of symptoms most likely might benefit from acute CTA to streamline further diagnostics and therapy.

\section{Background}

TIA is a well-known predictor for a manifest ischemic stroke with an incidence over $10 \%$ within three months after the index TIA. Nearly half of the TIA-patents develop a recurrent ischemic stroke within the first 48 hours. [1] Scores have been developed to quantify the risk of a pending stroke after TIA like the ABCD2-Score[2], the ABCD3-Score[3] and the Stroke Prognosis Instrument-II (SPI-II)[4]. To reduce the risk for a pending ischemic stroke following a TIA, it is important to perform a full diagnostic workup to identify common etiologic causes like ipsilateral vascular stenosis or occlusion as well as their treatment. With a consequent workup and early treatment in specialised clinics the risk for recurring strokes can be reduced below $3,5 \%$ after 90 days. $[5,6]$

Patients with TIA, based on intrinsic thrombolytic mechanisms and cerebral collateral status, can present with transient ischemic symptoms despite severe stenosis, dissection of brain supplying vessels, acute occlusion of pre-existing stenosis or as a result of an acute embolic occlusion of large cerebral vessels. [7] In this respect, current guidelines recommend managing TIA patients the same way as patients with a manifest stroke in the emergency department including the consideration to perform a CT-angiography of 
the brain supplying arteries.[8-10] However, macroangiopathic causes like arterial stenosis or occlusion account for around $23 \%$ of all TIA-cases.[11, 12] Moreover, the attestation of vascular findings in the CTA allows preventive treatment with medication and maintaining haemodynamic stability or may even have a direct impact on the acute treatment of the TIA-patient e. g. for a dissection with hemodynamic relevance, intravascular thrombi or an acute large vessel occlusion. Only the targeted diagnosis of one of those pathologies justifies possible side effects of CTA-imaging like the $2 \%$ risk of nephrotoxicity and the $0,01 \%$ risk of allergic contrast agent reaction as well as additional radiation exposure which is two times higher than a nativ CT-scan.[13-15]

The aim of our study was the systematic evaluation of the role of CTA imaging in the acute setting of TIA, to evaluate which subgroups of TIA patients benefit from the initial imaging with CTA and to test the predictive value of TIA scores regarding ipsilateral vascular pathologies.

\section{Methods}

\section{Patient population and study design}

In this retrospective study, clinical and neuroradiological data were collected from patients with the admission diagnosis TIA, being treated in a tertiary university hospital between September 2015 and March 2018, see Figure 1. Patients with insufficient data and change of diagnosis during in hospital stay were excluded. Due to the patient identification modus a high number of the excluded patients have been follow up cases in our vascular outpatient clinic and not admitted via the emergency department. Other exclusions were due to treatment refusal were the diagnosis was made but no work-up was performed. In some excluded cases patients suffered from obvious TIA-mimics like intoxication or hypoglycaemia. The remaining 833 TIA-patients were categorised into three subgroups: 1) no or low-grade stenosis, 2) ipsilateral vascular pathology and 3) intervention. A stenosis was considered as low-grade if it was occluding under $50 \%$ of the vessel, according to the North American Symptomatic Carotid Endarterectomy Trial (NASCET) [16], ipsilateral to the affected vascular territory. Stenosis over $50 \%$ were considered as high-grade. The second group involves only high-risk pathologies like high-grade stenosis, vascular dissection, complete occlusions or intraarterial thrombi, ipsilateral to the affected territory. Patients receiving interventions like IVT, MT, surgical (CEA) or interventional treatment (CAS) were assorted to group 3 .

Data was obtained by the Emergency Medical Service documentation, the clinics digital patient documentation system ixserv (ixmid Software Technologie $\mathrm{GmbH}$ ) and the intensive care information system IntelliSpace Critical Care and Anaesthesia (Philips). The collected data included baseline characteristics like age and sex, initial assessment, kind of symptoms, symptom duration and National Institute of Health Stroke Scale (NIHSS), lab results, patient's medical history and pre-medication. The results of stroke-imaging and cranial doppler-ultrasound were included. Finally, we documented if the patients received intravenous thrombolysis (IVT), mechanical thrombectomy (MT), carotid endarterectomy (CEA) or carotid percutaneous transluminal angioplasty without stenting (PTA only) or 
with stenting (CAS). From all available data we calculated every patients ABCD2-Score, ABCD3-Score and Stroke Prognosis Instrument II. [2-4] The ABCD2-score considers the items age, blood pressure, neurologic symptoms, duration of symptoms and diabetes. The ABCD3-score adds the item TIA within the last seven days. The SPI-II focus more on pre-existing conditions like heart failure, coronary heart disease, history of stroke and diabetes. It is completed by the items age, blood pressure and duration of symptoms over 24 hours.

\section{Statistical Analysis}

Statistical analysis was performed with Statistica (Version 13.3, TIBCO Software Inc.). Baseline characteristics were described using frequencies, means and median with standard deviation and interquartile range, as applicable. Groups were compared using ANOVA, Kruskal-Wallis test and $\chi^{2}$ test, as appropriate. Predictors for ipsilateral vascular pathologies were included in a multivariate logistic regression model if they predicted the vascular pathology with a p-value $\leq 0.1$ in a univariate logistic regression. A second regression model was developed for the need of interventional treatment. Items that would possibly cause interference, due to a certain causal similarity, were excluded.

\section{Results}

In total, 1034 patients with the admission diagnosis 'TIA' were screened, from which 833 were finally included in the study. Of these 833 patients, 549 (65.9\%) received immediate CTA in the emergency department, all other included patients (284), received CTA in the course of their hospital stay.. Baseline characteristics are given in Table 1 and the symptoms presented on first examination are described in Table 2. Using the imaging data of the 549 patients receiving a CTA in the emergency department, 126 (23.0\%) patients showed a high-grade ipsilateral arterial pathology: 94 (17.1\%) were found with highgrade, ipsilateral arterial stenosis, $20(3.6 \%)$ patients with a haemodynamic relevant, ipsilateral arterial occlusion, $6(1.1 \%)$ patients with an arterial dissection and $2(0.4 \%)$ patients with instable intraarterial thrombi. Of the 126 patients with high-grade ipsilateral arterial pathology, 40 (7.3\%) received invasive treatment because of the diagnosed ipsilateral pathology: 20 (3.6\%) patients received CEA, 11 (2\%) received CAS, $4(0,7 \%)$ patients received PTA without stenting, $4(0.7 \%)$ patients received an IVT and one $(0.2 \%)$ patient received subclavian-carotid bypass surgery. None of the patients received an MT on the basis of the acute CTA. In contrast, from all 284 patients without acute CTA, 3 (1.1\%) patients were diagnosed with high-grade ipsilateral vascular pathology (stenosis) via doppler-ultrasound during in hospital stay; one $(0.4 \%)$ patient underwent CEA. Patients with high grade, ipsilateral arterial pathology were more likely to be male $(p=0,044)$, had lower duration of symptoms $(p=0.045)$, were more likely to have a history of arterial hypertension $(p=0.096)$, atrial fibrillation $(p=0.031)$, coronary artery disease $(p=0.003)$ and myocardial infarction $(p=0.001)$ as well as were more likely to take antiplatelet $(p<0.001)$, antihypertensive $(p=0.077)$ and lipid-lowering medication $(p<0.001)$.

Table 1: Baseline characteristics $(\mathrm{n}=833)$ 


\begin{tabular}{|c|c|c|c|c|}
\hline Item & $\begin{array}{l}\text { No or Low-grade stenosis } \\
\qquad(\mathrm{n}=707)\end{array}$ & $\begin{array}{l}\text { Ipsilateral vascular pathology } \\
(\mathrm{n}=86)\end{array}$ & $\begin{array}{c}\text { Intervention } \\
(\mathrm{n}=40)\end{array}$ & $\begin{array}{c}\text { p- } \\
\text { Value* }\end{array}$ \\
\hline \multicolumn{5}{|l|}{ Demographic data: } \\
\hline Sex, male $(n, \%)$ & $372(52.6)$ & $54(62.8)$ & $25(62.5)$ & 0.044 \\
\hline Age, years \pm SD & $71 \pm 14$ & $72 \pm 13$ & $68 \pm 11$ & 0.371 \\
\hline \multicolumn{5}{|l|}{ Presentation in Hospital: } \\
\hline $\begin{array}{l}\text { Systolic blood pressure, } \\
\mathrm{mmHg} \pm \mathrm{SD}\end{array}$ & $151 \pm 27$ & $152 \pm 26$ & $145 \pm 21$ & 0.415 \\
\hline NIHSS (median, IQR) & $0(0-1)$ & $0(0-1)$ & $0(0-1)$ & 0.577 \\
\hline Duration of symptoms: & & & & 0.045 \\
\hline$<10 \min$ & $107(15.1)$ & $19(22.1)$ & $12(30.0)$ & \\
\hline$<60 \min$ & $19(2.7)$ & $18(20.9)$ & $11(27.5)$ & \\
\hline$>60 \mathrm{~min}$ & $435(61.5)$ & $49(57.0)$ & $17(42.5)$ & \\
\hline \multicolumn{5}{|c|}{ Cerebro-vascular and cardio-vascular risk factors: } \\
\hline Arterial hypertension (n, \%) & $568(80.3)$ & $73(84.9)$ & $36(90.0)$ & 0.096 \\
\hline Hyperlipidaemia (n, \%) & $604(85.4)$ & $72(83.7)$ & $37(92.5)$ & 0.433 \\
\hline Atrial fibrillation (n, \%) & $151(21.4)$ & $26(30.2)$ & $4(10.0)$ & 0.031 \\
\hline Diabetes mellitus (n, \%) & $173(24.5)$ & $20(23.3)$ & $10(25.0)$ & 0.956 \\
\hline Obesity (n, \%) & $120(17.0)$ & $15(17.4)$ & $12(30.0)$ & 0.110 \\
\hline Coronary heart disease (n, \%) & $103(14.6)$ & $22(25.6)$ & $9(22.5)$ & 0.003 \\
\hline Heart failure (n, \%) & $94(13.3)$ & $12(14.0)$ & $6(15.5)$ & 0.843 \\
\hline Myocardial infarction (n, \%) & $51(7.2)$ & $14(16.3)$ & $4(10.0)$ & 0.001 \\
\hline Aortic valve stenosis (n, \%) & $40(5.7)$ & $5(5.8)$ & $2(5.0)$ & 0.844 \\
\hline Chronic kidney disease (n, \%) & $108(15.3)$ & $15(17.4)$ & $7(17.5)$ & 0.665 \\
\hline $\mathrm{PFO}(\mathrm{n}, \%)$ & $97(13.7)$ & $12(14.0)$ & $4(10.0)$ & 0.401 \\
\hline PFO + atrial aneurysm $(n, \%)$ & $24(3.4)$ & $0(0)$ & $0(0)$ & 0.111 \\
\hline Pulmonal embolism (n, \%) & $9(1.3)$ & $1(1.2)$ & $1(2.5)$ & 0.796 \\
\hline DVT (n, \%) & $16(2.3)$ & $0(0)$ & $0(0)$ & 0.234 \\
\hline Procoagulant disease $(n, \%)$ & $18(2.5)$ & $0(0)$ & $0(0)$ & 0.194 \\
\hline History of cancer (n, \%) & $78(11.0)$ & $10(11.6)$ & $3(7.5)$ & 0.766 \\
\hline $\begin{array}{l}\text { History of ischaemic stroke (n, } \\
\%)\end{array}$ & $142(20.1)$ & $25(19.1)$ & $9(22.5)$ & 0.152 \\
\hline $\begin{array}{l}\text { TIA within the last seven days } \\
(\mathrm{n}, \%)\end{array}$ & $87(12.3)$ & $11(27.5)$ & $9(10.4)$ & 0.173 \\
\hline \multicolumn{5}{|l|}{ Medication: } \\
\hline Antiplatelet medication (n, \%) & $247(34.9)$ & $41(47.7)$ & $22(55.0)$ & $<0.001$ \\
\hline $\begin{array}{l}\text { Dual antiplatelet medication } \\
(\mathrm{n}, \%)\end{array}$ & $17(2.4)$ & $7(8.1)$ & $1(2.5)$ & $<0.001$ \\
\hline NOAK (n, \%) & $50(7.0)$ & $6(7.0)$ & $3(7.5)$ & 0.994 \\
\hline Marcumar (n \%) & $67(9.5)$ & $12(14.0)$ & $2(5.0)$ & 0.244 \\
\hline $\begin{array}{l}\text { Antihypertensive medication } \\
(\mathrm{n}, \%)\end{array}$ & $525(74.3)$ & $69(80.2)$ & $34(85.0)$ & 0.077 \\
\hline Antihyperlipidemic medication & $254(35.9)$ & $47(54.7)$ & $22(55.0)$ & \\
\hline
\end{tabular}

NIHSS: National Institute of Health Stroke Scale; IQR: interquartile range; PFO: persistant foramen ovale; DVT: deep vein thrombosis; NOAK: new oral anticoagulants; SD: standard deviation; * via ANOVA or Kruskal-Wallis test or $\chi^{2}$ 
Table 2: Symptoms on presentation $(\mathrm{n}=833)$

\begin{tabular}{|c|c|c|c|c|}
\hline Item & $\begin{array}{l}\text { No or Low-grade stenosis } \\
\qquad(\mathrm{n}=707)\end{array}$ & $\begin{array}{l}\text { Ipsilateral vascular pathology } \\
\qquad(\mathrm{n}=86)\end{array}$ & $\begin{array}{l}\text { Intervention } \\
\qquad(\mathrm{n}=40)\end{array}$ & $\begin{array}{c}\text { p- } \\
\text { Value* }\end{array}$ \\
\hline \multicolumn{5}{|l|}{ Motor function: } \\
\hline $\begin{array}{l}\text { Contralateral motor } \\
\text { weakness, n (\%) }\end{array}$ & $248(35.1)$ & $29(33.7)$ & $23(57.5)$ & 0.014 \\
\hline Facial palsy, n (\%) & $133(18.8)$ & $15(17.4)$ & $9(22.5)$ & 0.794 \\
\hline Dysarthria, n (\%) & $159(22.5)$ & $23(26.7)$ & $7(17.5)$ & 0.488 \\
\hline Pyramidal signs**, n (\%) & $16(2.3)$ & $1(1.2)$ & $4(10.0)$ & 0.007 \\
\hline \multicolumn{5}{|l|}{ Sensory function: } \\
\hline Hemihypoaesthesia, n (\%) & $152(21.5)$ & $19(22.1)$ & $12(30.0)$ & 0.450 \\
\hline Aphasia, n (\%) & $203(28.7)$ & $16(18.6)$ & $11(27.5)$ & 0.141 \\
\hline Double vision, n (\%) & $39(5.5)$ & $3(3.5)$ & $0(0)$ & 0.236 \\
\hline Hemianopsia, n (\%) & $39(5.5)$ & $4(4.7)$ & $2(5.0)$ & 0.939 \\
\hline Loss of vision, n (\%) & $69(9.8)$ & $7(8.1)$ & $7(17.5)$ & 0.236 \\
\hline \multicolumn{5}{|l|}{ Others: } \\
\hline Vertigo, n (\%) & $135(19.1)$ & $28(32.6)$ & $3(7.5)$ & 0.002 \\
\hline Cephalgia, n (\%) & $48(6.8)$ & $7(8.1)$ & $2(5.0)$ & 0.801 \\
\hline Unconciousness, n (\%) & $21(3.0)$ & $6(7.0)$ & $2(5.0)$ & 0.139 \\
\hline Seizure, n (\%) & $0(0)$ & $0(0)$ & $0(0)$ & 1.000 \\
\hline \multicolumn{5}{|l|}{ Affected circulation: } \\
\hline Anterior, n(\%) & $568(80.3)$ & $47(54.7)$ & $39(97.5)$ & \\
\hline Posterior, n(\%) & 139 (19.7) & $39(45.3)$ & $1(2.5)$ & \\
\hline
\end{tabular}

Using the ABCD2-, ABCD3- and the SPI-II-Score, we found no significant difference between the three subgroups (Table 3). These TIA scores showed no predictive value for the diagnosis of high grade ipsilateral vascular pathologies or for the need of surgical or interventional treatment after the correction for possible confounders.

Table 3: Comparison of TIA-Scores as a predictor for ipsilateral stenosis in need of therapy $(n=833)$ 


\begin{tabular}{|c|c|c|c|c|}
\hline TIA Scores & $\begin{array}{l}\text { No or Low-grade stenosis } \\
\qquad(\mathrm{n}=707)\end{array}$ & $\begin{array}{l}\text { Ipsilateral vascular pathology } \\
\qquad(\mathrm{n}=86)\end{array}$ & $\begin{array}{l}\text { Intervention } \\
\quad(\mathrm{n}=40)\end{array}$ & $\begin{array}{c}\mathrm{p}- \\
\text { Value* }\end{array}$ \\
\hline $\begin{array}{l}\text { ABCD2-Score (median, } \\
\text { IQR) }\end{array}$ & $4(3-5)$ & $4(3-5)$ & $4.5(3,5-5,5)$ & 0.577 \\
\hline $\begin{array}{l}\text { ABCD3-Score (median, } \\
\text { IQR) }\end{array}$ & $4(3-6)$ & $4(3-5)$ & $5(4-6)$ & 0.199 \\
\hline SPI-II (median, IQR) & $3(1-5)$ & $3(2-6)$ & $3(1-5)$ & 0.144 \\
\hline
\end{tabular}

IQR: interquartile range, * via Kruskal-Wallis test

From all possible clinical characteristics associated with high grade ipsilateral vascular pathology given in Table 1 and 2, univariate logistic regression revealed male sex (OR 1.64, 1.11-2.43 95\% Cl; p=0.014), duration of symptoms (OR 0.74, 0.58-0.94 95\% Cl; $p=0.012)$, coronary heart disease (OR 2.13, 1.36-3.34 95\% Cl; $p=0.002$ ), Aphasia (OR 1.48; 0.94-2.16 95\% Cl; $p=0.093$ ) and Unconsciousness (OR 0.45; 0.20-1.04 $95 \% \mathrm{Cl} ; \mathrm{p}=0.063$ ) as possible predictors. In a multivariate logistic regression model including these items coronary heart disease (OR 2.13, 1.35-3.39 95\% Cl; $p=0.001$ ) and a short duration of the symptoms (OR $0.7,0.55-0,8995 \% \mathrm{Cl} ; \mathrm{p}=0.004)$ remained as significant predictors for ipsilateral vascular pathologies (Table 4).

Table 4 Multivariate logistic regression for ipsilateral vascular pathology

\begin{tabular}{lcccc}
\hline Item & Regression Coefficient for depending ipsilateral pathology & p-Value & OR & $95 \%$ CI \\
\hline Sex, male & 0.397 & 0.052 & 1.482 & $0.995-2.223$ \\
Duration of Symptoms & -0.356 & 0.004 & 0.701 & $0.550-0.892$ \\
\hline Coronary heart disease & 0.758 & 0.001 & 2.134 & $1.345-3.385$ \\
\hline Aphasia & 0.360 & 0.123 & 1.433 & $0.906-2.268$ \\
\hline Unconsciousness & -0.797 & 0.069 & 0.451 & $0.191-1.064$ \\
Intercept & -0.335 & 0.744 & 0.715 & $0.095-5.376$ \\
\hline
\end{tabular}

A similar logistic regression model was developed to identify possible predictors for the need of any invasive treatment. The univariate logistic regression identified the items duration of symptoms (OR 0.61, 0.42-0.89 95\% Cl; $p=0,009)$, obesity (OR 2.09; 1.04-4.22 95\% Cl; $p=0.039$ ) and contralateral motor weakness (OR 2.52; 1.32-4.80 95\% $\mathrm{Cl} ; \mathrm{p}=0.005$ ) as possible predictors for intervention. A multivariate logistic regression model of these items identified duration of symptoms (OR $0.55 ; 0.37-0.8195 \% \mathrm{Cl}$; $\mathrm{p}=0.003)$, obesity (OR $2.30 ; 1.12-4.7395 \% \mathrm{Cl} ; \mathrm{p}=0,023)$ and contralateral motor weakness (OR1.77; $1.27-$ $2.4795 \% \mathrm{Cl} ; \mathrm{p}=0.001$ ) as predictive (Table 5).

Table 5 Multivariate logistic regression for Intervention

\begin{tabular}{lcrrr}
\hline Item & Regression Coefficient for depending intervention & p-Value & OR & $95 \%$ CI \\
\hline Duration of Symptoms & & & & \\
\hline Atrial fibrillation & -0.605 & 0.003 & 0.546 & $0.368-0.810$ \\
\hline Obesity & -0.991 & 0.066 & 0.371 & $0.129-1.070$ \\
\hline Contralateral motor weakness & 0.833 & 0.023 & 2.300 & $1.118-4.732$ \\
\hline Intercept & 0.569 & 0.001 & 1.766 & $1.265-2.466$ \\
\hline
\end{tabular}




\section{Discussion}

In our study, we found high grade, ipsilateral arterial pathologies in around $23 \%$ of all patients with TIA diagnosed by acute CTA and a need for invasive treatment in around $7 \%$ of cases. These numbers indicate that CTA in the acute setting of TIA is justified in selected patient subgroups. As predictors, we identified cardiovascular disease and a short period of symptoms which might be useful for patient selection. In contrast, established TIA-scores turned out to be not predictive for high risk vascular pathologies.

TIA and ischemic stroke, both indistinguishable in the acute setting in most cases, require vascular imaging. Besides CTA, there are other imaging methods to be considered for neurovascular status evaluation like magnetic resonance imaging and neurovascular ultrasound. Neurovascular ultrasound of the brain supplying arteries has a high spatial resolution and is able to detect atherosclerotic changes, as well as thrombi in the proximal carotid artery very well. However, it is limited by investigator dependency and availability. Neurovascular Ultrasound in the acute setting can also result in treatment delays due to longer investigation times and patient factors like incompliance, anatomical problems like insufficient transtemporal doppler window and the fact that distal intracranial arteries as well as distal parts of the internal carotid arteries cannot be visualized. [17] Therefore, neurovascular ultrasound is not performed on a usual basis in the acute phase of ischemic stroke if fast and targeted therapy like IVT and EVT is available.[18] Magnetic resonance imaging (MRI) is one of the most important methods to assess the brain tissue. However, it has been shown that CT combined with CTA provides a comparable quality to diffusion-weighted MRI in stroke patients.[19] Considering the fact that MRI resources are more limited compared to CT, which is available $24 / 7$ in all stroke centres, also is significantly faster and has a high sensitivity for the diagnosis of vessel occlusions and haemorrhages, CT imaging is the technology of choice in the acute setting of stroke.[20]

The evaluated $A B C D 2$-score, $A B C D 3$-score and SPI-II, that stratify the risk for stroke after TIA, were not predictive for ipsilateral vascular pathologies or the need for invasive treatment in our study. This observation corresponds to findings from Lou et al. concerning the ABCD2-Score as a possible predictor for intervention. In their study, including 121 patients with TIA, they found that the ABCD2-Score was equally distributed in patients no matter if they received an intervention or not.[21] Reasons for the missing predictive value of these scores might be, that TIA scores have been developed to predict recurrence rates of TIA or stroke in those patients. Many factors incorporated in these scores (admission blood pressure, age, diabetes mellitus and heart failure) were equally distributed in our cohort, raising the suspicion, that these factors are likely to be usable to quantify instability (risk of recurrence) of the underlying pathology, but are not predictive for the underlying pathology itself. Also, most items are related to the neurologic symptoms presented at admission. As the most important predictors for vascular disease like chronic arterial hypertension, high heart rate, smoking habit and other vascular diseases are not considered in these scores, this might explain the lack of prediction. [22, 23] 
Our results advise to consider a certain risk profile if to decide to perform a CTA or not. Except the fact that patients with acute stroke symptoms should undergo immediate CTA. Patients with coronary heart disease or obesity and therefore a high risk for macroangiopathic vessel disease and TIA should receive CTA to diagnose high risk vascular pathologies and to initiate targeted therapy. CTA in this case could contribute to a time gain to diagnosis and could contribute to reduce the risk for TIA recurrence or a manifest ischemic stroke. For example, patients with symptomatic high-grade stenosis and poor vascular flow and collateralisation status are at high risk to suffer from early disabling stroke. [24] A CTA could reveal the stenosis and vascular flow. Therefore, it possibly affects treatment decisions. Another study found de novo dual antiplatelet therapy (OR 3.24) as a predictor for spontaneous recanalization in patients with symptomatic acute extracranial carotid occlusion. [25] As well dual antiplatelet therapy reduces the risk of recurrent stroke after TIA or minor stroke. [26-28] Information like these could be gained by CTA and cause a vital impact on treatment. Nevertheless, currently there is no known study to the authors which displays a direct link between early CTA and a benefit from early or careful treatment. It can only be assumed and needs further research.

A short duration of Symptoms in TIA patients is likely to be associated with macroangiopathic arterial disease of brain supplying arteries and can be found in most patients with carotid artery stenosis. A prototype of a short lasting neurologic deficit associated with carotid artery stenosis is the Amaurosis fugax, a special form of TIA.[29, 30] Already in the seventies Pessin et al. and Harrison et al. found that TIA-patients with a symptom duration under one hour were more likely to have a carotid artery stenosis and should get an angiography.[31, 32] These findings go in line with our finding, that a short duration of symptoms increases the risk for a high grade, ipsilateral vascular pathology and the need for an invasive treatment in patients with TIA. In contrast, cardiac emboli are more likely to cause permanent and more severe focal neurological deficits.[33-35] The difference in duration of symptoms caused by arterial or cardiac emboli could be explained by a difference in spontaneous revascularization due to a variation of constitution and size of the thrombi.[32, 36, 37] Another point to consider is the collateralisation status in patients with arterial emboli caused by vessel stenosis compared to cardiac embolization with no associated vessel stenosis. Arterial stenosis formation take month to years inducing intracranial collateralization, which is not present in cardiac embolization. This fact could explain short symptom duration in patients with arterial stenosis, where hemodynamics can adapt in a few seconds.[38] Therefore, short duration of symptom should not be discarded as trivial by the clinician, but raise the suspicion of macroangiopathic disease with associated findings in CTA. TIA in crescendo was previously shown to significantly correlate with large artery atherosclerosis as the origin of TIA. [39] This correlation couldn't be confirmed by our observations, e. g. table 1.

A contralateral motor weakness is more often seen in patients needing an intervention than in the other subgroups,and therefore it is predicting this circumstance. This symptom is highly associated with the anterior circulation, which is affected in $97.5 \%$ of all cases in the subgroup that needed an intervention.

Strength of our study is the high number of patients included in our study cohort as well as the use of "real word" data from a large volume, tertiary stroke centre. Limitations include the monocentric, 
retrospective design of the study. Moreover, a selection bias must be assumed, as only $66 \%$ of patients with TIA received a CTA in the emergency department. The reason for the decision to perform or not to perform a CTA in the acute setting could be influenced by multiple factors like preference of the consultant neurologist in charge, patient factors like kidney disease and medical history of the patient. Another weakness is the lack of MRI data, therefore a mixture of TIA and minor-stroke patients is to assume for our population. If more MRI data would have been available, the results of our study would possibly change. But this displays everyday praxis and the current lack of MRI imaging even in large stroke centers. [40]

Beside the shown results our study indicates further research on important information's like the follow up on patients and how CTA influences their therapy and outcome compared to other imaging methods like neurovascular ultrasound.

\section{Conclusion}

In this study CTA revealed high grade ipsilateral pathology in more than every fifth patient with TIA and therefore represents an important diagnostic tool in initial workup. History of coronary heart disease, obesity, contralateral motor weakness and a short duration of symptoms may be useful to triage TIA patients for acute CTA. Our findings justify a prospective, randomized trial comparing patients receiving early neurovascular ultrasound, early CTA and usual care. We want to emphasise that every patient with an persistent acute focal neurologic deficit on emergency department presentation needs immediate vascular imaging, as at this stage a TIA is not to distinguish from a stroke favouring based CT-imaging.

\section{Abbreviations}

\begin{tabular}{|l|l|}
\hline CAS & carotid artery stenting \\
\hline CEA & carotid endarterectomy \\
\hline CTA & computed tomography angiography \\
\hline IVT & intravenous thrombolysis \\
\hline MRI & Magnetic resonance imaging \\
\hline MT & mechanical thrombectomy \\
\hline PTA & percutaneous transluminal angioplasty \\
\hline SPI-II & stroke prognosis instrument II \\
\hline TIA & transient ischaemic attack \\
\hline
\end{tabular}

\section{Declarations}


Ethics approval and consent to participate: The ethics commission of the University Medicine Göttingen waived an ethical approval. Written informed consent was obtained from the patient(s) for their participation in this study.

Consent for publication: Not applicable

Availability of data and materials: All data generated or analysed during this study are included in this published article

Competing interests: The Authors declare that there is no conflict of interests.

Funding: The authors received no financial support for the research, authorship, and/or publication of this article.

Authors' contributions: GH, IM, MP and JL conceived the study. GH and IM were involved in the protocol development. GH and IM wrote the first draft of the manuscript and qualify equally for the first authorship. All authors provided continuous evaluation during the study process. All authors reviewed and edited the manuscript and approved the final version of the manuscript.

Acknowledgement: Not applicable.

\section{References}

1. Easton JD, Saver JL, Albers GW, Alberts MJ, Chaturvedi S, Feldmann E, et al. Definition and evaluation of transient ischemic attack: a scientific statement for healthcare professionals from the American Heart Association/American Stroke Association Stroke Council; Council on Cardiovascular Surgery and Anesthesia; Council on Cardiovascular Radiology and Intervention; Council on Cardiovascular Nursing; and the Interdisciplinary Council on Peripheral Vascular Disease. The American Academy of Neurology affirms the value of this statement as an educational tool for neurologists. Stroke. 2009;40:2276-93. doi:10.1161/STROKEAHA.108.192218.

2. Fothergill $A$, Christianson TJH, Brown RD, Rabinstein AA. Validation and refinement of the ABCD2 score: a population-based analysis. Stroke. 2009;40:2669-73.

doi:10.1161/STROKEAHA.109.553446.

3. Merwick Á, Albers GW, Amarenco P, Arsava EM, Ay H, Calvet D, et al. Addition of brain and carotid imaging to the $A B C D 2$ score to identify patients at early risk of stroke after transient ischaemic attack: a multicentre observational study. The Lancet Neurology. 2010;9:1060-9. doi:10.1016/S1474-4422(10)70240-4.

4. Kernan WN, Viscoli CM, Brass LM, Makuch RW, Sarrel PM, Roberts RS, et al. The stroke prognosis instrument II (SPI-II) : A clinical prediction instrument for patients with transient ischemia and nondisabling ischemic stroke. Stroke. 2000;31:456-62. 
5. Valls J, Peiro-Chamarro M, Cambray S, Molina-Seguin J, Benabdelhak I, Purroy F. A Current Estimation of the Early Risk of Stroke after Transient Ischemic Attack: A Systematic Review and Meta-Analysis of Recent Intervention Studies. Cerebrovasc Dis. 2017;43:90-8. doi:10.1159/000452978.

6. Lavallée PC, Meseguer E, Abboud H, Cabrejo L, Olivot J-M, Simon O, et al. A transient ischaemic attack clinic with round-the-clock access (SOS-TIA): feasibility and effects. Lancet Neurol. 2007;6:953-60. doi:10.1016/S1474-4422(07)70248-X.

7. Nadarajan V, Perry RJ, Johnson J, Werring DJ. Transient ischaemic attacks: mimics and chameleons. Pract Neurol. 2014;14:23-31. doi:10.1136/practneurol-2013-000782.

8. Powers WJ, Rabinstein AA, Ackerson T, Adeoye OM, Bambakidis NC, Becker K, et al. Guidelines for the Early Management of Patients With Acute Ischemic Stroke: 2019 Update to the 2018 Guidelines for the Early Management of Acute Ischemic Stroke: A Guideline for Healthcare Professionals From the American Heart Association/American Stroke Association. Stroke. 2019;50:e344-e418. doi:10.1161/STR.0000000000000211.

9. Deutsche Gesellschaft für Neurologie. S1-Leitlinie Akuttherapie des ischämischen Schlaganfalls. 0. O.: Arbeitsgemeinschaft der Wissenschaftlichen Medizinischen Fachgesellschaften; 2012.

10. Deutsche Gesellschaft für Neurologie. S2k-Leitlinie Akuttherapie des ischämischen Schlaganfalls Ergänzungen 2015. o. O.: Arbeitsgemeinschaft der Wissenschaftlichen Medizinischen Fachgesellschaften; 2015.

11. Amarenco P, Lavallée PC, Monteiro Tavares L, Labreuche J, Albers GW, Abboud H, et al. Five-Year Risk of Stroke after TIA or Minor Ischemic Stroke. N Engl J Med. 2018;378:2182-90. doi:10.1056/NEJMoa1802712.

12. Purroy F, Montaner J, Molina CA, Delgado P, Ribo M, Alvarez-Sabín J. Patterns and predictors of early risk of recurrence after transient ischemic attack with respect to etiologic subtypes. Stroke. 2007;38:3225-9. doi:10.1161/STROKEAHA.107.488833.

13. Mnyusiwalla A, Aviv RI, Symons SP. Radiation dose from multidetector row CT imaging for acute stroke. Neuroradiology. 2009;51:635-40. doi:10.1007/s00234-009-0543-6.

14. Dittrich R, Akdeniz S, Kloska SP, Fischer T, Ritter MA, Seidensticker P, et al. Low rate of contrastinduced Nephropathy after CT perfusion and CT angiography in acute stroke patients. $J$ Neurol. 2007;254:1491-7. doi:10.1007/s00415-007-0528-5.

15. Hunt $\mathrm{CH}$, Hartman RP, Hesley GK. Frequency and severity of adverse effects of iodinated and gadolinium contrast materials: retrospective review of 456,930 doses. AJR Am J Roentgenol. 2009;193:1124-7. doi:10.2214/AJR.09.2520.

16. North American Symptomatic Carotid Endarterectomy Trial. Methods, patient characteristics, and progress. Stroke. 1991;22:711-20. doi:10.1161/01.str.22.6.711.

17. Hennerici M, Rautenberg W, Sitzer G, Schwartz A. Transcranial doppler ultrasound for the assessment of intracranial arterial flow velocity-Part 1. Examination technique and normal values. Surgical Neurology. 1987;27:439-48. doi:10.1016/0090-3019(87)90251-5. 
18. Deutsche Gesellschaft für Neurologie. S1-Leitlinie: Diagnostik akuter zerebrovaskulärer Erkrankungen. ○. O.: Arbeitsgemeinschaft der Wissenschaftlichen Medizinischen Fachgesellschaften; 2017.

19. Schramm P, Schellinger PD, Fiebach JB, Heiland S, Jansen O, Knauth M, et al. Comparison of CT and CT angiography source images with diffusion-weighted imaging in patients with acute stroke within 6 hours after onset. Stroke. 2002;33:2426-32. doi:10.1161/01.str.0000032244.03134.37.

20. Coutts SB, Modi J, Patel SK, Demchuk AM, Goyal M, Hill MD. CT/CT angiography and MRI findings predict recurrent stroke after transient ischemic attack and minor stroke: results of the prospective CATCH study. Stroke. 2012;43:1013-7. doi:10.1161/STROKEAHA.111.637421.

21. Lou M, Safdar A, Edlow JA, Caplan L, Kumar S, Schlaug G, et al. Can ABCD2 score predict the need for in-hospital intervention in patients with transient ischemic attacks? Int J Emerg Med. 2010;3:7580. doi:10.1007/s12245-010-0176-x.

22. Sutton-Tyrrell K, Alcorn HG, Wolfson SK, Kelsey SF, Kuller LH. Predictors of carotid stenosis in older adults with and without isolated systolic hypertension. Stroke. 1993;24:355-61. doi:10.1161/01.str.24.3.355.

23. Mathiesen EB, Joakimsen $\mathrm{O}, \mathrm{B} \emptyset n a a \mathrm{KH}$. Prevalence of and risk factors associated with carotid artery stenosis: the Troms $\varnothing$ Study. Cerebrovasc Dis. 2001;12:44-51. doi:10.1159/000047680.

24. Blaser T, Hofmann K, Buerger T, Effenberger O, Wallesch C-W, Goertler M. Risk of stroke, transient ischemic attack, and vessel occlusion before endarterectomy in patients with symptomatic severe carotid stenosis. Stroke. 2002;33:1057-62. doi:10.1161/01.str.0000013671.70986.39.

25. Hause S, Oldag A, Breja A, Neumann J, Wilcke J, Schreiber S, et al. Acute symptomatic extracranial internal carotid occlusion - natural course and clinical impact. Vasa. 2020;49:31-8. doi:10.1024/0301-1526/a000826.

26. Johnston SC, Amarenco P, Denison H, Evans SR, Himmelmann A, James S, et al. Ticagrelor and Aspirin or Aspirin Alone in Acute Ischemic Stroke or TIA. N Engl J Med. 2020;383:207-17. doi:10.1056/NEJMoa1916870.

27. Johnston SC, Easton JD, Farrant M, Barsan W, Conwit RA, Elm JJ, et al. Clopidogrel and Aspirin in Acute Ischemic Stroke and High-Risk TIA. N Engl J Med. 2018;379:215-25. doi:10.1056/NEJMoa1800410.

28. Wang Y, Wang Y, Zhao X, Liu L, Wang D, Wang C, et al. Clopidogrel with aspirin in acute minor stroke or transient ischemic attack. N Engl J Med. 2013;369:11-9. doi:10.1056/NEJMoa1215340.

29. Kvickström P, Lindblom B, Bergström G, Zetterberg M. Amaurosis fugax: risk factors and prevalence of significant carotid stenosis. Clin Ophthalmol. 2016;10:2165-70. doi:10.2147/OPTH.S115656.

30. Smit RL, Baarsma GS, Koudstaal PJ. The source of embolism in amaurosis fugax and retinal artery occlusion. Int Ophthalmol. 1994;18:83-6. doi:10.1007/bf00919244.

31. Pessin MS, Duncan GW, Mohr JP, Poskanzer DC. Clinical and angiographic features of carotid transient ischemic attacks. N Engl J Med. 1977;296:358-62. doi:10.1056/NEJM197702172960703. 
32. Harrison MJ, Marshall J, Thomas DJ. Relevance of duration of transient ischaemic attacks in carotid territory. Br Med J. 1978;1:1578-9. doi:10.1136/bmj.1.6127.1578.

33. Inzitari D, Eliasziw M, Gates P, Sharpe BL, Chan RK, Meldrum HE, Barnett HJ. The causes and risk of stroke in patients with asymptomatic internal-carotid-artery stenosis. North American Symptomatic Carotid Endarterectomy Trial Collaborators. N Engl J Med. 2000;342:1693-700. doi:10.1056/NEJM200006083422302.

34. Lin HJ, Wolf PA, Kelly-Hayes M, Beiser AS, Kase CS, Benjamin EJ, D'Agostino RB. Stroke severity in atrial fibrillation. The Framingham Study. Stroke. 1996;27:1760-4. doi:10.1161/01.str.27.10.1760.

35. Yip PK, Jeng JS, Lee TK, Chang YC, Huang ZS, Ng SK, Chen RC. Subtypes of ischemic stroke. A hospital-based stroke registry in Taiwan (SCAN-IV). Stroke. 1997;28:2507-12. doi:10.1161/01.str.28.12.2507.

36. Niesten JM, van der Schaaf IC, van Dam L, Vink A, Vos JA, Schonewille WJ, et al. Histopathologic composition of cerebral thrombi of acute stroke patients is correlated with stroke subtype and thrombus attenuation. PLoS ONE. 2014;9:e88882. doi:10.1371/journal.pone.0088882.

37. Boeckh-Behrens T, Schubert M, Förschler A, Prothmann S, Kreiser K, Zimmer C, et al. The Impact of Histological Clot Composition in Embolic Stroke. Clin Neuroradiol. 2016;26:189-97. doi:10.1007/s00062-014-0347-x.

38. Henderson RD, Eliasziw M, Fox AJ, Rothwell PM, Barnett HJ. Angiographically defined collateral circulation and risk of stroke in patients with severe carotid artery stenosis. North American Symptomatic Carotid Endarterectomy Trial (NASCET) Group. Stroke. 2000;31:128-32. doi:10.1161/01.str.31.1.128.

39. Purroy F, Jiménez Caballero PE, Gorospe A, Torres MJ, Alvarez-Sabin J, Santamarina E, et al. Recurrent transient ischaemic attack and early risk of stroke: data from the PROMAPA study. $J$ Neurol Neurosurg Psychiatry. 2013;84:596-603. doi:10.1136/jnnp-2012-304005.

40. Chaturvedi S, Ofner S, Baye F, Myers LJ, Phipps M, Sico JJ, et al. Have clinicians adopted the use of brain MRI for patients with TIA and minor stroke? Neurology. 2017;88:237-44. doi:10.1212/WNL.0000000000003503.

\section{Figures}




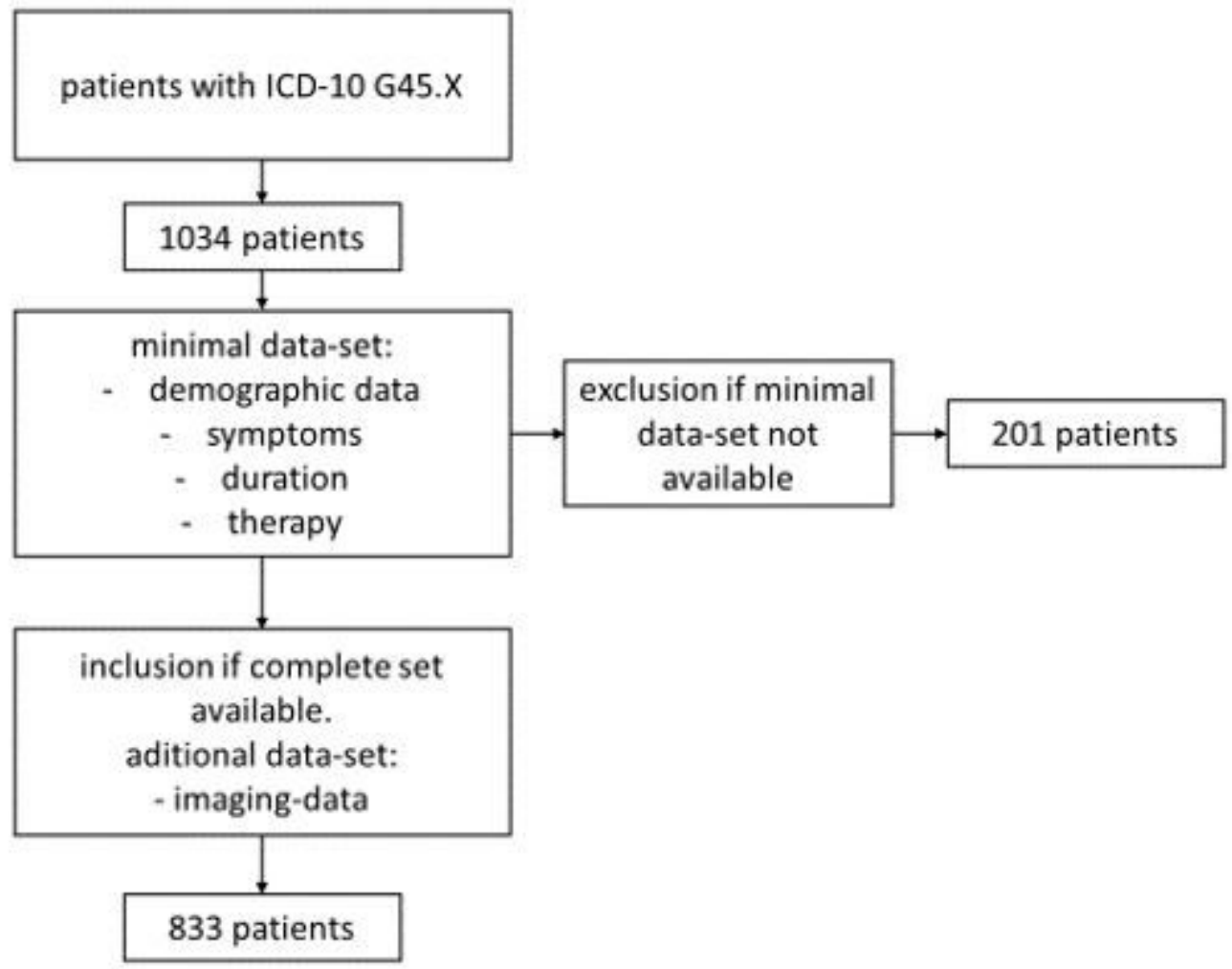

Figure 1

Inclusion chart 